\title{
The spectrum of bone disease in 200 chronic hemodialysis patients: a correlation between clinical, biochemical and histological findings
}

Department of Pathology and Department of Internal Medicine, Universidade Federal Fluminense - Niterói, Brazil

\begin{abstract}
Introduction: Renal osteodystrophy includes the complete range of mineral metabolism disorders that affect the skeleton in patients with chronic renal failure. Patients and Methods: 200 patients with end-stage renal disease and on dialysis were investigated regarding the clinical, biochemical and histological findings of bone disease. Results: The spectrum of renal osteodystrophy consisted mainly of high turnover bone lesions $(74.5 \%)$, including osteitis fibrosa in $57.5 \%$. Patients with mild bone disease were on dialysis for shorter periods of time and were mostly asymptomatic. Patients with aluminum-related bone disease (16.5\%) had the greatest aluminum exposure, either orally or parenterally, and together with patients with high turnover mixed disease, were the most symptomatic. Although on a non-regular basis, the vast majority of the patients ( $82.5 \%)$ had been receiving vitamin $D$. The incidence of adynamic bone disease was high $(n=8)$ among parathyroidectomized patients $(n=12)$. Significantly higher serum levels of alkaline phosphatase were observed in osteitis fibrosa. Conclusions: The use of calcitriol and phosphate-binding agents on a non-regular basis seems to be the reason for the apparent reduced response to the treatment of secondary hyperparathyroidism. Alkaline phosphatase has been shown to be a fair marker for bone turnover in patients with osteitis fibrosa. The severity of the clinical manifestations of bone disease correlates with the histological features of bone lesion and to the time spent on dialysis.
\end{abstract}

Uniterms: Renal osteodystrophy. Chronic renal failure. Hemodialysis. Aluminum intoxication. Bone metabolism.

\section{INTRODUCTION}

$\mathrm{T}$ he term renal osteodystrophy is used to describe the skeletal syndromes and alterations in mineral metabolism associated with end-stage renal disease. ${ }^{1}$ It is a multifactorial disorder of bone remodeling consisting of either high-turnover (secondary hyperparathyroidism) or low-turnover bone disease (pure

\author{
Address for correspondence: \\ Maria Eugênia Leite Duarte \\ Universidade Federal Fluminense, Hospital Universitário \\ Antônio Pedro, Departamento de Patologia \\ Rua Marquês de Paraná 303, $4^{\circ}$ andar \\ Niterói/RJ - Brasil - CEP 24030-000
}

osteomalacia, aluminum-related or non-aluminum related adynamic bone disease), or consisting of mixed high and low-turnover bone disease. ${ }^{2}$ Because the distinction between high-turnover and low-turnover lesions of renal osteodystrophy depends, in part, on measurements of the dynamics of bone remodeling, transition from one histologic subtype to another may occur. Thus, renal osteodystrophy should be viewed as a continuum with a spectrum of histologic manifestations, ranging from osteomalacia and low-turnover bone disease to osteitis fibrosa and high-turnover bone lesions. ${ }^{3}$

During the 1970 s and 1980 s, aluminum was recognized as an important factor in the pathogenesis of several subtypes of renal osteodystrophy. ${ }^{4,5}$ Most patients with the skeletal lesions of osteomalacia and many with the adynamic lesions of renal osteodystrophy show 
evidence of substantial aluminum deposition in bones, whereas this finding is much less common in those with secondary hyperparathyroidism and osteitis fibrosa. ${ }^{5,6}$

The maintenance of normal serum levels of calcium and phosphorus to prevent further hyperplasia of the parathyroid glands, ${ }^{1}$ the introduction of continuous ambulatory peritoneal dialysis, the improved results in kidney transplantation, ${ }^{7}$ the therapeutic administration of active vitamin $\mathrm{D}$ sterols such as 1,25 dihydroxy vitamin $\mathrm{D}^{1}$ and the recognition of the risk of aluminum intoxication from cumulative ingestion of aluminum-containing medications ${ }^{8,9}$ are among the major approaches to the successful management of patients with renal osteodystrophy.

The present study was aimed at studying the correlation between clinical, biochemical and histological features of renal bone disorders in 200 patients with chronic renal failure treated with long-term hemodialysis.

\section{METHODS}

\section{Study Patients}

Initially, 293 patients with end-stage renal disease under maintenance hemodialysis in the Rio de Janeiro metropolitan area were considered for participation in this study. All these patients had previously been submitted to an iliac crest bone biopsy in the periods 1987-1988 and 1990-1995 for the investigation of bone disease. Iliac crest bone biopsies were performed in those patients with clinical findings of bone disease, such as unexplained bone pain, proximal myopathy or fractures; and/or altered laboratory parameters, such as persistently high plasma phosphorus concentrations, uncontrollable hypercalcemia, high plasma alkaline phosphatase or parathyroid hormone concentrations. Ninety-three patients were excluded from the study on the grounds of being under continuous ambulatory peritoneal dialysis (CAPD), being pre-dialysis patients, having previous renal transplantation, not providing the medical and/or laboratory information requested on the questionnaire and failing to ingest the tetracycline before the biopsy procedure. Thus, 200 patients from eight different dialysis units formed the material for this study.

The vast majority of the biopsies were performed at Hospital Universitário Antônio Pedro (Universidade Federal Fluminense) and all samples were processed and examined by a single observer in the Department of Pathology of the same University. Clinical, laboratory and risk parameters for bone disease of these patients were investigated according to a standardized questionnaire. The clinical parameters assessed at the time of bone biopsy included muscle weakness, unexplained bone pain and pathological fractures. All blood samples for subsequent measurements of serum levels of total albumin, calcium, phosphorus and alkaline phosphatase were collected before dialysis and the values are expressed as the average of the three most recent measurements. All patients were on regular hemodialysis and the concentration of calcium in the dialysate was 3.5 $\mathrm{mEq} / \mathrm{liter}$. Calcium carbonate or acetate was used as the primary phosphate-binding agent in most subjects, and doses were adjusted according to the phosphorus serum levels. Aluminum containing antacids was used as a phosphate binder in a smaller number of patients.

\section{Bone Biopsy}

All the study patients underwent an iliac crest needle biopsy under local anesthesia. Patients were given two courses of tetracycline separated by an interval of 11 days. The biopsy was performed 3-10 days after the last dose of tetracycline. The bone samples were fixed in $70 \%$ ethanol and dehydrated by sequential changes in ascending concentrations of ethanol and xylene and then embedded in methyl methacrylate. For histological analysis, undecalcified sections $(5 \mathrm{~mm})$ of cortical and trabecular bone were stained by the Goldner method ${ }^{10}$ and by aurintricarboxylic acid for detection of aluminum. ${ }^{11,12}$ Bone remodeling and turnover was investigated on $10 \mathrm{~mm}$ unstained sections under fluorescent light.

\section{Classification of bone lesions}

The histologic classification for the skeletal lesions of renal osteodystrophy used in this study has been previously described $\mathrm{d}^{1,2}$ as follows:

a) osteitis fibrosa: increased remodeling, resorption and formation, increase in bone-forming cell proliferation ${ }^{13}$ and bone marrow fibrosis;

b) mild disease: slightly increased bone remodeling and no fibrosis;

c) osteomalacia: increased osteoid volume and surface, defective mineralization;

d) adynamic disease: hypocellular bone surfaces, no remodeling;

e) mixed disease: features of both osteitis fibrosa and osteomalacia.

These histologic diagnoses were combined into two major groups: high-turnover bone disease (osteitis fibrosa, mild lesion and mixed disease with a prevalence of osteitis 
fibrosa) and low-turnover bone disease (osteomalacia, adynamic disease and mixed disease with a prevalence of osteomalacia). The low turnover group (osteomalacia, adynamic and mixed disease, predominantly osteomalacia) was further divided, according to the presence or absence of stainable bone surface aluminum, into aluminum bone disease (stainable aluminum on $\geq 25 \%$ of bone surfaces) and non-aluminum bone disease.

\section{Statistical analysis}

Differences between the means of laboratory measurements for all studied groups were tested for statistical significance using analysis of variance (ANOVA) followed by Student's t-test.

\section{RESULTS}

\section{Patient characteristics}

The mean age of the 200 patients was $40.7 \pm 14.8$ years (range 11-74), and 53.5\% were men. The patients had been hemodialyzed for $73.8 \pm 48.3$ months (range 1-192). In $93 \%$ of the patients, the water used for the preparation of dialysis solutions was purified by deionization. Aluminumcontaining phosphate binding agents were intermittently used for the control of hyperphosphatemia in $70.5 \%$ of the patients. Ninety-four percent of the patients had been treated with calcium carbonate or acetate and $82.5 \%$ with vitamin $\mathrm{D}$ on a non-regular basis. Parathyroidectomy had been performed in twelve patients $(7 \%)$ for the treatment of severe secondary hyperparathyroidism. Bone aluminum deposition on $\geq 25 \%$ of bone surfaces was detected in $16.5 \%$ of the patients (Fig. 1).

\section{Bone histology}

Overall, $57.5 \%$ of the patients had osteitis fibrosa, $12.5 \%$ had mild bone disorder and $4.5 \%$ had mixed bone disease, predominantly with features of osteitis fibrosa. The distribution of patients with low turnover disorders, either aluminum or non-aluminum bone disease, was as follows: $11 \%$ had aplastic bone disease, $7.5 \%$ had osteomalacia and $7 \%$ had mixed bone disease, predominantly osteomalacia (Figs. 2 to 5). Patient characteristics divided according to bone disorder are shown in Table 1 . The patients with low turnover bone diseases were further divided according to the presence or absence of stainable bone aluminum.

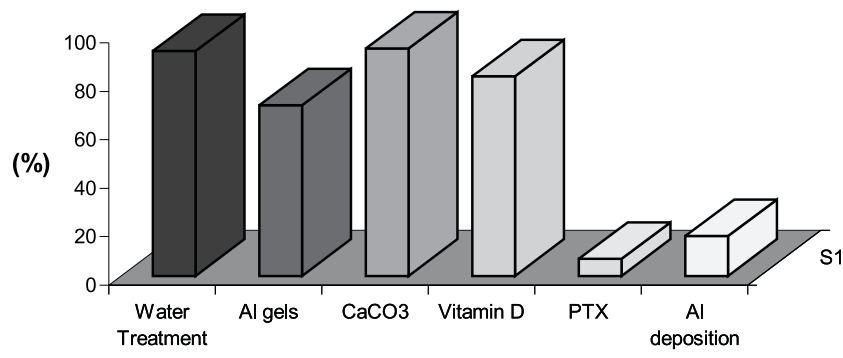

Figure 1 - Distribution of 200 dialysis patients according to the use of purified water in the dialysis solutions, aluminum gels, calcium carbonate or acetate, vitamin D, parathyroidectomy (PTX) and deposition of aluminum in $\geq 25 \%$ of all bone surfaces.

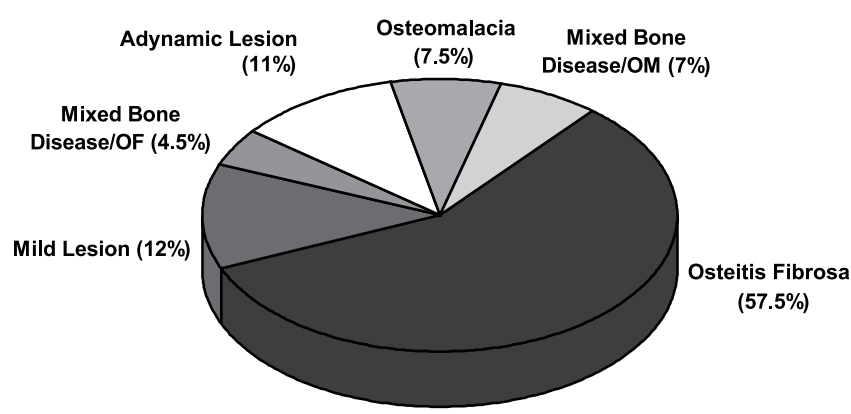

Figure 2 - Distribution of 200 dialysis patients according to the histological type of bone disease.

On average, patients were in similar age groups. Patients with low turnover non-aluminum bone disease tended to be slightly younger. Those with mild bone disease had been treated by dialysis for shorter periods of time. It was observed that patients with aluminum-related bone disease had undergone the greatest exposure to inadequately treated water or aluminum gels. The vast majority of patients had received calcium carbonate or acetate. Although on a non-regular basis, $82.5 \%$ of all patients had received vitamin $\mathrm{D}$ at some time since beginning dialysis. Twelve patients, 4 with osteitis fibrosa and 8 with non-aluminum low turnover bone disease, had previously been treated by parathyroidectomy. The histochemical stain for aluminum was positive in $\geq 25 \%$ of the bone surfaces in $83 \%$ of the patients with aluminumrelated bone disease. Aluminum deposition was related to the osteomalacic component of the disease in $22.3 \%$ of the patients with high turnover mixed bone disease.

The clinical and laboratory findings are displayed in Table 2. Most of the patients with mild bone disease were asymptomatic whereas patients with aluminum bone disease and mixed bone disease, predominantly osteitis fibrosa, were the most symptomatic. The levels of total albumin were similar among the groups as well as total calcium and plasma phosphorus. As expected, patients with osteitis fibrosa and high turnover mixed disease had the highest plasma alkaline phosphatase concentrations. 
High-turnover bone disease

$(n=149)$



(\%)

Figure 3 - Distribution of patients with high-turnover bone disease. OF = osteitis fibrosa.

\section{Low-turnover non-aluminum bone disease}

$(n=22)$

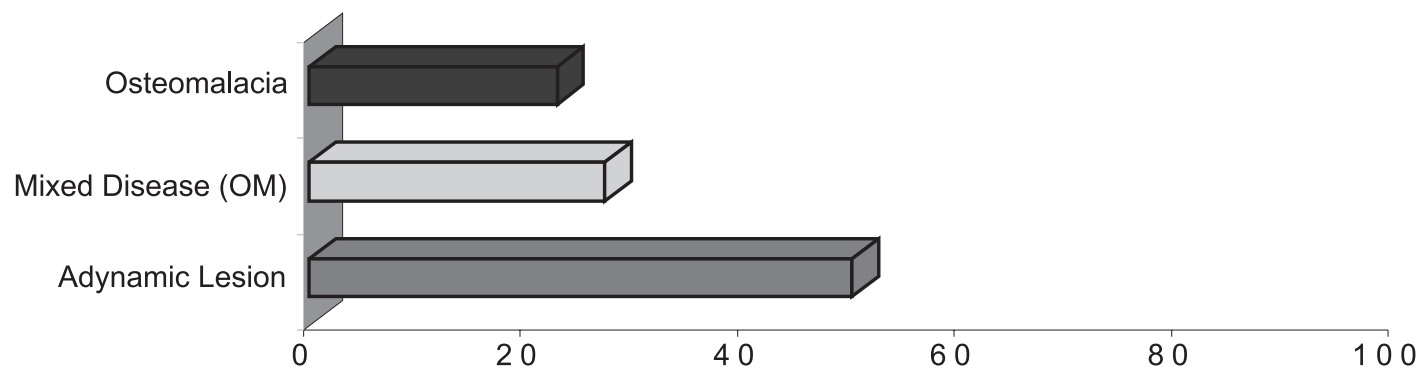

$(\%)$

Figure 4 - Distribution of patients with low-turnover non-aluminum bone disease. $\mathrm{OM}=$ osteomalacia.

\section{Low-turnover non-aluminum bone disease}

$(n=22)$

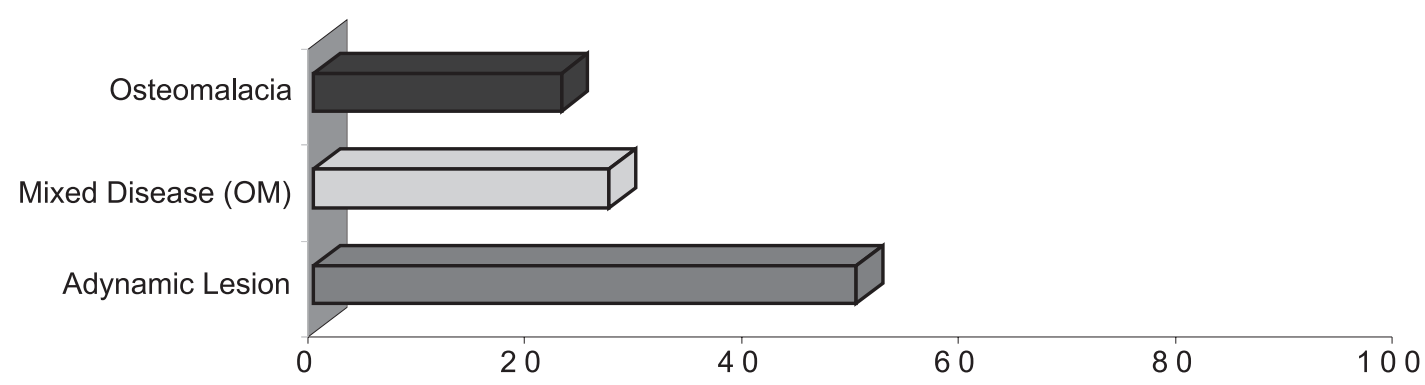

$(\%)$

Figure 5 - Distribution of patients with low-turnover aluminum bone disease. $\mathrm{OM}=0$ osteomalacia.

\section{DISCUSSION}

The results of the present study demonstrate that high turnover bone diseases, especially osteitis fibrosa, are the commonest bone disorders associated with chronic renal failure. Furthermore, important risk factors for bone disease including dialysis duration, water treatment, vitamin D usage and the patient's exposure to toxic agents such as aluminum have been shown to play an important role in the determination of the type of bone lesion.

It is well established that aluminum accumulates in the bones of patients undergoing maintenance dialysis. ${ }^{14-17}$ This may be due to parenteral exposure to inadequately treated water for dialysis solutions and/or the use of large amounts of aluminum-containing phosphate binding agents for prolonged periods. ${ }^{5,18-20}$ In the last decade, the use of adequate water purification methods for the preparation of 
Table 1

Characteristics of $\mathbf{2 0 0}$ dialysis patients subdivided according to the bone remodeling turnover, type of bone disease and stainable aluminum bone deposition.

\begin{tabular}{|c|c|c|c|c|c|}
\hline & \multicolumn{3}{|c|}{$\begin{array}{l}\text { High turnover bone disease } \\
\qquad(n=149)\end{array}$} & \multicolumn{2}{|c|}{$\begin{array}{l}\text { Low turnover bone disease } \\
\qquad(\mathrm{n}=51)\end{array}$} \\
\hline & $\begin{array}{l}\text { Osteitis } \\
\text { fibrosa } \\
(n=115)\end{array}$ & $\begin{array}{l}\text { Mild bone } \\
\text { disorder } \\
(n=25)\end{array}$ & $\begin{array}{c}\text { Mixed bone } \\
\text { disease, } \\
\text { predominantly } \\
\text { osteitis fibrosa } \\
(n=9)\end{array}$ & $\begin{array}{l}\text { Aluminum bone } \\
\text { disease }^{*} \\
(n=29)\end{array}$ & $\begin{array}{c}\text { Non-aluminum } \\
\text { bone disease } \\
\quad(n=22)\end{array}$ \\
\hline Age (years)* & $40.9(15.0)$ & $36.4(13.2)$ & $46.2(14.1)$ & $47.0(16.6)$ & $34.5(9.67)$ \\
\hline $\operatorname{Sex}(M / F)$ & $1: 1$ & $2.6: 1$ & $0.5: 1$ & $1.2: 1$ & $1.7: 1$ \\
\hline Duration of dialysis (months)* & $76.8(47.4)$ & $50(44.1)$ & $91.5(44.8)$ & $73.7(36.1)$ & $77.8(56.4)$ \\
\hline Water treatment $(\%)$ & 95.7 & 100 & 100 & 72.4 & 95.5 \\
\hline Use of $\mathrm{Al}(\mathrm{OH})_{3}(\%)$ & 72.1 & 48 & 77.8 & 89.7 & 50 \\
\hline $\mathrm{CaCO}_{3} /$ acetate (\%) & 93 & 88 & 89 & 100 & 96 \\
\hline Vitamin D therapy (\%) & 82.6 & 80 & 66.7 & 93.1 & 77.3 \\
\hline Parathyroidectomy (\%) & 3.5 & - & - & - & 36.4 \\
\hline Bone stainable Al $\oplus 25 \%$ surfaces (\%) & 4.3 & - & 22.3 & 83 & - \\
\hline
\end{tabular}

* includes aplastic bone disorder, osteomalacia and mixed bone disease.

* Values expressed as mean and standard desviation.

Table 2

Clinical and laboratory findings in $\mathbf{2 0 0}$ dialysis patients subdivided according to the bone remodeling turnover, type of bone disease and stainable aluminum bone deposition.

\begin{tabular}{|c|c|c|c|c|c|}
\hline & \multicolumn{3}{|c|}{$\begin{array}{l}\text { High turnover bone disease } \\
\qquad(n=149)\end{array}$} & \multicolumn{2}{|c|}{$\begin{array}{l}\text { Low turnover bone disease } \\
\qquad(n=51)\end{array}$} \\
\hline & $\begin{array}{l}\text { Osteitis } \\
\text { fibrosa } \\
(n=115)\end{array}$ & $\begin{array}{l}\text { Mild bone } \\
\text { disorder } \\
(n=25)\end{array}$ & $\begin{array}{c}\text { Mixed bone } \\
\text { disease, } \\
\text { predominantly } \\
\text { osteitis fibrosa } \\
(n=9)\end{array}$ & $\begin{array}{l}\text { Aluminum bone } \\
\text { disease }^{\star} \\
(n=29)\end{array}$ & $\begin{array}{c}\text { Non-aluminum } \\
\text { bone } \\
\text { disease }^{*} \\
(n=27)\end{array}$ \\
\hline Miopathy (\%) & 49.6 & 36 & 78 & 69 & 36.4 \\
\hline Fracture (\%) & 20.9 & 8 & 22 & 34.5 & 27.3 \\
\hline Bone pain (\%) & 71.3 & 24 & 100 & 89.7 & 68.2 \\
\hline Total calcium $(\mathrm{mg} / \mathrm{dl})^{* *}$ & $8.8(1.5)$ & $9.3(0.9)$ & $7.9(1.5)$ & $9.1(1.5)$ & $8.9(1.1)$ \\
\hline Phosphorus $(\mathrm{mg} / \mathrm{dl})^{* *}$ & $5.6(1.7)$ & $5.6(1.8)$ & $4.9(1.1)$ & $5.0(1.2)$ & $5.1(1.8)$ \\
\hline Total albumin $(g \%)^{\star *}$ & $3.8(0.5)$ & $4.0(0.3)$ & $3.6(0.6)$ & $4.0(0.6)$ & $4.0(0.5)$ \\
\hline Alkaline phosphatase $(\mathrm{U} / \mathrm{I})^{* *}$ & $888.2(203.7)^{\S}$ & $268.6(135.6)$ & $660(82.1)^{\S}$ & $159.1(94.82)$ & $436(108.6)$ \\
\hline
\end{tabular}

* includes aplastic bone disorder, osteomalacia and mixed bone disease (predominantly osteomalacia).

** Values expressed as mean and standard desviation.

$\$ p<0.05$ versus mild and low turnover bone diseases.

dialysis solutions and the avoidance of aluminum-containing gels for the control of hyperphosphatemia have significantly decreased the incidence of aluminum intoxication in dialyzed patients. ${ }^{3}$ In the present study, a small number of patients $(7 \%)$ was found to have been exposed to untreated water during the last decade. This was more commonly observed in patients receiving dialysis in small, non-urban centers, where the control of water purification methods was not very rigorous. Aluminum-containing phosphate binding gels, another potential source of aluminum exposure, were occasionally used by $70 \%$ of the studied patients. Our data demonstrates that patients with the highest aluminum exposure, either orally or parenterally, had heavy aluminum bone deposition ( $\oplus 25 \%$ of bone surfaces) detected by histochemical techniques. These patients either had low turnover bone lesion (adynamic lesion or osteomalacia) or the aluminum accounted for the osteomalacic component of mixed bone disorder. These two aluminum exposure sources accounted for $16.5 \%$ of the observed aluminumrelated bone disease. 
In the $1980 \mathrm{~s},{ }^{6,21,22}$ and more recently, ${ }^{8}$ the prevalence of aluminum-related bone disease in patients undergoing hemodialysis was reported as approaching 30\%. Our results show that this figure has decreased substantially. Both clinical and experimental data indicate that aluminum impairs skeletal mineralization and diminishes bone cell activity. ${ }^{23,24}$

Aluminum deposition in bones is often found within the mineralization front, which is located at the junction between osteoid seams and the mineralized bone. ${ }^{3}$ At this site, calcification of newly formed bone collagen is initiated and aluminum has been shown to disrupt the mineralization process, slowing the rate of formation and growth of hydroxy apatite crystals. ${ }^{23}$

The proliferation and differentiation of osteoblast precursors into mature cells are both impaired by aluminum. A characteristic finding in aluminum-related bone disease is the decrease in osteoblast numbers, with reductions in collagen synthesis and mineralized bone formation. Together, these changes account for the development of adynamic bone lesion and osteomalacia. ${ }^{3}$

Alterations in the metabolism of vitamin D and in mineral homeostasis, and disturbances in the control of PTH synthesis, are the major factors in the pathogenesis of renal osteodystrophy. In the treatment of patients with symptomatic renal osteodystrophy, daily oral doses of calcitriol have been reported to diminish bone pain, improve muscle strength and resolve osteitis fibrosa partially or completely. ${ }^{25-27}$

Despite the use of calcitriol for the treatment of secondary hyperparathyroidism in $82.5 \%$ of this population of patients, osteitis fibrosa, at various degrees of severity, was the commonest disorder $(57.5 \%)$ of renal osteodystrophy. The use of calcitriol and calciumcontaining agents on a non-regular basis and in many instances in insufficient doses, could be the reason for the diminished therapeutic response of calcitriol in controlling the development and improvement of established osteitis fibrosa.

The efficacy of active vitamin D sterols is well-known in the treatment of secondary hyperparathyroidism..$^{28,29}$ The administration of active vitamin D sterols can be accomplished either based on a daily schedule of administration or, alternatively, in large intermittent doses of oral or intravenous calcitriol. ${ }^{28,29}$ Unfortunately, a great number of patients in this study were unable to afford the treatment with vitamin D compounds, resulting in the use of this compound on a non-regular basis and in insufficient doses.

Prior to parathyroidectomy, aluminum intoxication must be excluded ${ }^{30}$ and the diagnosis of severe osteitis fibrosa should be well-documented by biochemical, radiographic and, whenever possible, by bone biopsy means. It is well-established that patients who have undergone previous parathyroidectomy may respond less well or not at all to deferoxamine (DFO) therapy for aluminum removal..$^{31}$ Furthermore, for patients who may subsequently undergo renal transplantation, partial resection should be considered (subtotal parathyroidectomy). The preservation of some parathyroid tissue may help to maintain calcium homeostasis after renal function is restored. ${ }^{1}$

Parathyroidectomy has been reported to ameliorate the symptoms of hyperparathyroidism in hemodialysis and transplant patients. Recurrent disease has been observed in $22 \%$ of hemodialysis patients and has rarely been seen in transplant recipients. ${ }^{32}$

In the present study, subtotal parathyroidectomy was considered as the treatment of choice in 12 patients with advanced secondary hyperparathyroidism. Indications for parathyroidectomy included extraskeletal calcifications, calciphylaxis, intractable pruritus, persistent hypercalcemia or its development during calcitriol therapy, and unsuccessful management of hyperphosphatemia via the regular use of phosphate-binding antacids. ${ }^{30,33}$

Parathyroidectomy surgery led to the development of adynamic bone disease in 8 patients and ameliorated the severity of osteitis fibrosa in the other 4 patients. For these reasons, parathyroidectomy should be carefully considered in the treatment of secondary hyperparathyroidism.

Alkaline phosphatase values are considered fair markers for the severity of secondary hyperparathyroidism and, among the studied hemodialysis population, those with osteitis fibrosa had higher serum alkaline phosphatase concentrations. The bone isoenzyme of alkaline phosphatase is expressed by osteoblasts, and high serum levels normally reflect the extent of high turnover lesions and their values frequently correlate with serum PTH levels. ${ }^{34}$ Thus, alkaline phosphatase measurements can be useful for monitoring the skeletal response to treatment with vitamin D sterols in patients with osteitis fibrosa. Hyperphosphatemia, when observed in isolated cases, was corrected by dietary phosphorus restriction and the use of phosphate binding agents. Similarly to phosphates, serum calcium levels did not differ among the various patient groups.

Among the symptoms investigated, bone pain was the most common. Patients with high turnover mixed bone disease and aluminum bone disorder were the most symptomatic. It is well-established that severe bone pain is a clinical hallmark of aluminum-related bone disease. ${ }^{35}$ However, there is marked variation among patients, and some with advanced secondary hyperparathyroidism are severely incapacitated. ${ }^{1}$ Patients treated by dialysis for 
shorter periods of time $(50 \pm 44.1$ months $)$ tended to be younger ( $36.4 \pm 13.2$ years), were less symptomatic and also had less evidence of histological bone lesion (mild bone disease subgroup). Although the symptoms of renal osteodystrophy are nonspecific,,$^{30}$ our results suggest that the severity of the clinical manifestations of bone disease correspond with the histological features of bone lesion, which in turn may be related to the time on dialysis. The physiologic basis of the uremic myopathy is not wellunderstood and the role of abnormal vitamin D metabolism remains uncertain. ${ }^{30}$ Proximal myopathy was the second most frequently observed symptom in all groups except the mild bone disorder subgroup.

In conclusion, we have observed in the studied population, consisting of 200 patients with end-stage renal disease under maintenance hemodialysis, that the spectrum of renal osteodystrophy was comprised mostly of osteitis fibrosa. Our results have shown that, in comparison to previously published data, ${ }^{6,8,21,22}$ the prevalence of

\section{REFERENCES}

1. Goodman WG, Coburn JW, Ramirez JA, Slatopolsky E, Salusky IB. Renal osteodystrophy in adults and children. In: Favus DM, editor. Primer on the metabolic bone diseases and disorders of mineral metabolism. New York: Raven Press 1996;341-60.

2. Hruska KA, Teitelbaum SL. Renal osteodystrophy. N Engl J Med 1995;333:166-74.

3. Goodman WG, Duarte MEL. Aluminum: effects on bone and role in the pathogenesis of renal osteodystrophy. Miner Electrolyte Metab 1991;17:221-32.

4. Coburn JW, Norris KC, Nebeker HG. Osteomalacia and bone disease arising from aluminum. Semin Nephrol 1986;6:68-89.

5. Sherrard DJ, Ott SM, Maloney NA, Andress DI, Coburn JW. Renal osteodystrophy. Semin Nephrol 1986;6:56-67.

6. Llach F, Felsenfeld AJ, Coleman MD, Pederson JA. Prevalence of various types of bone disease in dialysis patients. In: Robinson RR, editor. Proceedings of the ninth international congress of nephrology. New York: SpringerVerlag 1984;1375-82.

7. Sherrard DJ, Hercz G, Pei Y, et al. The spectrum of bone disease in end-stage renal failure: an evolving disorder. Kidney Int 1993;43:436-42.

8. Pei Y, Hercz G, Greenwood C, et al. Risk factors for renal osteodystrophy: a multivariant analysis. J Bone Miner Res 1995; 10:149-56.

9. Salusky IB. Bone and mineral metabolism in childhood endstage renal disease. Pediatr Clin North Am 1995;42:1531-50. aluminum intoxication and aluminum-related bone disease is small $(16.5 \%)$ in the studied population. Furthermore, the incidence of aluminum-related bone disease was prevalent in those patients with the greatest aluminum exposure, either orally or parenterally. The use of calcitriol on a non-regular basis and in insufficient doses, seems to be the reason for its apparent reduced effectiveness in the treatment of secondary hyperparathyroidism. Parathyroid surgery should be carefully considered in the treatment of secondary hyperparathyroidism, as this may lead to the development of adynamic bone disease. Alkaline phosphatase has been shown to be a good marker of bone turnover with significantly higher values observed in patients with osteitis fibrosa. Bone pain was the most common symptom in patients with high turnover mixed bone disease and aluminum bone disorder. The severity of the clinical manifestations of bone disease correlates with the histological features of bone lesion and to the time on dialysis.

10. Villanueva AR, Mehr LA. Modifications of the Goldner and Gomori one-step trichrome stains for plastic-embedded thin sections of bone. Am J Medical Technology 1977;43:536-8.

11. Andress DI, Maloney NA, Coburn JW, Endress DB, Sherrard DJ. Osteomalacia and aplastic bone disease in aluminumrelated osteodystrophy. J Clin Endocrinol Metabol 1987;65:11-6.

12. Maloney NA, Ott AS, Alfrey AC, Miller NI, Coburn JW, Sherrard DJ. Histological quantitation of aluminum in iliac bone from patients with renal failure. J Lab Clin Med 1982;99:206-16.

13. Serrano S, Mariñoso ML, Torres A, et al. Osteoblastic proliferation in bone biopsies from patients with end-stage chronic renal failure. J Bone Min Res 1997;121:91-9.

14. Alfrey AC, Hegg A, Craswell P. Metabolism and toxicity of aluminum in renal failure. Am J Clin Nutr 1980;33:1509-16.

15. Hodsman AB, Sherrard DJ, Alfrey AC, et al. Bone aluminum and histomorphometric features of renal osteodystrophy. J Clin Endocrinol Metab 1982;54:539-46.

16. Parsons V, Davies C, Goode C, Ogg C, Siddiqui J. Aluminum in bone from patients with renal failure. Br Med J 1975;IV:273-5.

17. Sebert JL, Marie A, Gueris J, et al. Assessment of the aluminum overload and of its possible toxicity in asymptomatic uremic patients: evidence for a depressive effect on bone formation. Bone 1985;6:373-5.

18. Salusky IB, Foley J, Nelson P, Goodman WG. Aluminum accumulation during treatment with aluminum hydroxide and dialysis in children and young adults with chronic renal disease. N Engl J Med 1991;324:527-31. 
19. Sedman AB, Miller NL, Warady BA, Lum GM, Alfrey AC. Aluminum loading in children with chronic renal failure. Kidney Int 1984;26:201-4.

20. Winney RJ, Cowie JF, Robson JS. The role of plasma aluminum in the detection and prevention of aluminum toxicity. Kidney Int 1986;29:S91-5.

21. Ihle B, Buchanan M, Stevens B, et al. Aluminum associated bone disease: clinico-pathologic correlation. Am J Kidney Dis 1982;2:255-63.

22. Pierides AM, Edwards WG Jr, Cullu, US Jr, McCall JT, Ellis HA. Hemodialysis encephalopathy with osteomalacic fractures and muscle weakness. Kidney Int 1980;18:115-24.

23. Blumenthal NC, Posner AS. In vitro model of aluminuminduced osteomalacia: inhibition of hydroxyapatite formation and growth. Calcif Tissue Int 1984;36:439-41.

24. Parfitt AM. The localization of aluminum in bone: implications for the mechanism of fixation and for the pathogenesis of aluminum-related bone disease. Int J Artif Organs 1988;11:79-90.

25. Baker LR, Muir JW, Sharman VL. Controlled trial of calcitriol in hemodialysis patients. Clin Nephrol 1986;26:185-91.

26. Berl T, Berns AS, Huffer WE. 1,25-Dihydroxycholecalciferol effects in chronic dialysis: a double-blind controlled study. Ann Intern Med 1978;88:774-80.

27. Ott SM, Maloney NA, Coburn JW, Alfrey AC, Sherrard DJ. The prevalence of bone aluminum deposition in renal osteodystrophy and its relation to the response to calcitriol therapy. N Engl J Med 1982;307:709-13.

28. Fukagawa M, Kitaoka M, Kaname S. Suppression of parathyroid gland hyperplasia by $1,25(\mathrm{OH}) 2 \mathrm{D} 3$ pulse therapy. N Engl J Med 1990;315:421-2.
29. Martin KJ, Bullal HS, Domoto DT, Blalock S, Weindel M. Pulse oral calcitriol for the treatment of hyperparathyroidism in patients on continuous ambulatory peritoneal dialysis: preliminary observations. Am J Kidney Dis 1992;19:540-5.

30. Coburn JW, Slatopolsky E. Vitamin D, parathyroid hormone, and the renal osteodystrophies. In: Brenner B, Rector F, editors. The Kidney. $4^{\text {th }}$ ed. Philadelphia: WB Saunders 1990;2076-89.

31. Ott SM, Andress DL, Nebeker HG. Changes in bone histology after treatment with desferrioxamine. Kidney Int 1986;29:S108-13.

32. Neonakis E, Wheeler MH, Krishnan H, Coles GA, Davies F, Woodhead JS. Results of surgical treatment of renal hyperparathyroidism. Arch Surg 1995;130:643-8.

33. Llach F. Parathyroidectomy in chronic renal failure: indications, surgical approach, and the use of calcitriol. Kidney Int 1990; 38:S29.

34. Hruska KA, Teiltelbaum SL, Kopelman R. The predictability of the histological features of uremic bone disease by noninvasive techniques. Metab Bone Dis Rel Res 1978;1:39

44. Llach F, Felsenfeld AJ, Coleman MD, Keveney JJ Jr, Pederson JA, Medlock TR. The natural course of dialysis osteomalacia. Kidney Int 1986;29:S74-9.

\section{ACKNOWLEDGEMENTS}

This work was partly supported by $\mathrm{CNPq}$ grants through the Programa Institucional de Bolsas de Iniciação Científica - PIBIC / UFF.

\section{Resumo}

Introdução: A osteodistrofia renal compreende todas as formas de alterações do metabolismo mineral que afetam o tecido ósseo de pacientes renais crônicos. Pacientes e Métodos: 200 pacientes submetidos a diálise regular foram investigados quanto aos aspectos clínicos, laboratoriais e histopatológicos relacionados com doença óssea. Resultados: As lesões de alto turnover foram observadas em $74.5 \%$ dos pacientes, sendo que $57.5 \%$ eram portadores de osteíte fibrosa. Pacientes com lesão mínima estavam em diálise por menos tempo e em geral eram assintomáticos. Pacientes com osteopatia alumínica (16.5\%) tiveram a maior exposição ao alumínio por via oral e/ou parenteral e, ao lado dos portadores de doença mista de alto turnover, eram os mais sintomáticos. A grande maioria dos pacientes (82.5\%) fazia uso irregular de vitamina D. Foi alta a incidência de doença adinâmica $(n=8)$ nos pacientes paratireoidectomizados $(n=12)$. Na osteíte fibrosa foram observados os níveis mais elevados de fosfatase alcalina. Conclusões: A utilização de calcitriol e quelantes de fósforo de forma irregular e em doses insuficientes parece ter sido a principal causa para a resposta reduzida ao tratamento do hiperparatireoidismo secundário. A fosfatase alcalina pode ser considerada um bom marcador bioquímico do turnover ósseo. A intensidade das manifestações clínicas relacionadas com o sistema músculo esquelético correlacionam-se com o tipo histológico da lesão óssea e com o tempo em diálise. 